Wright State University

CORE Scholar

Mathematics and Statistics Faculty

Publications

Mathematics and Statistics

2006

\title{
Electrical Properties of Unintentionally Doped Semi-Insulating and Conducting $6 \mathrm{H}-\mathrm{SiC}$
}

William C. Mitchel

W. D. Mitchell

Z. Q. Fang

S. R. Smith

Helen Smith

Wright State University - Main Campus, helen.smith@wright.edu

See next page for additional authors

Follow this and additional works at: https://corescholar.libraries.wright.edu/math

Part of the Applied Mathematics Commons, Applied Statistics Commons, and the Mathematics Commons

\section{Repository Citation}

Mitchel, W. C., Mitchell, W. D., Fang, Z. Q., Smith, S. R., Smith, H., Khlebnikov, I., Khlebnikov, Y. I., Basceri, C., \& Balkas, C. (2006). Electrical Properties of Unintentionally Doped Semi-Insulating and Conducting $6 \mathrm{H}-$ SiC. Journal of Applied Physics, 100 (4), 43706.

https://corescholar.libraries.wright.edu/math/29

This Article is brought to you for free and open access by the Mathematics and Statistics department at CORE Scholar. It has been accepted for inclusion in Mathematics and Statistics Faculty Publications by an authorized administrator of CORE Scholar. For more information, please contact library-corescholar@wright.edu. 


\section{Authors}

William C. Mitchel, W. D. Mitchell, Z. Q. Fang, S. R. Smith, Helen Smith, Igor Khlebnikov, Y. I. Khlebnikov, C. Basceri, and C. Balkas 


\title{
Electrical properties of unintentionally doped semi-insulating and conducting $6 \mathrm{H}-\mathrm{SiC}$
}

\author{
W. C. Mitchel and W. D. Mitchell ${ }^{\mathrm{a})}$ \\ Air Force Research Laboratory, AFRL/MLPS, Wright Patterson Air Force Base (AFB), \\ 3005 Hobson Way, Ohio 45433-7707 \\ Z. Q. Fang and D. C. Look \\ Semiconductor Research Center, Wright State University, Dayton, Ohio 45435 \\ S. R. Smith and H. E. Smith \\ University of Dayton Research Institute, 300 College Park, Dayton, Ohio 45469 \\ Igor Khlebnikov, Y. I. Khlebnikov, C. Basceri, and C. Balkas \\ INTRINSIC Semiconductor Corp., 22660 Executive Drive, Suite 101, Dulles, Virginia 20166
}

(Received 4 April 2006; accepted 14 May 2006; published online 21 August 2006)

Temperature dependent Hall effect (TDH), low temperature photoluminescence (LTPL), secondary ion mass spectrometry (SIMS), optical admittance spectroscopy (OAS), and thermally stimulated current (TSC) measurements have been made on $6 H$-SiC grown by the physical vapor transport technique without intentional doping. $n$ - and $p$-type as well semi-insulating samples were studied to explore the compensation mechanism in semi-insulating high purity SiC. Nitrogen and boron were found from TDH and SIMS measurements to be the dominant impurities that must be compensated to produce semi-insulating properties. The electrical activation energy of the semi-insulating sample determined from the dependence of the resistivity was $1.0 \mathrm{eV}$. LTPL lines near 1.00 and $1.34 \mathrm{eV}$, identified with the defects designated as UD-1 and UD-3, were observed in all three samples but the intensity of the UD-1 line was almost a factor of 10 more in the $n$-type sample than in the the $p$-type sample with that in the semi-insulating sample being intermediate between those two. OAS and TSC experiments confirmed the high purity of this material. The results suggest that the relative concentrations of a dominant deep level and nitrogen and boron impurities can explain the electrical properties in this material. (C) 2006 American Institute of Physics. [DOI: 10.1063/1.2227622]

\section{INTRODUCTION}

Semi-insulating (SI) silicon carbide substrates are required for high power microwave devices and circuits based on $\mathrm{SiC}$ and $\mathrm{GaN}$. Because of its wide band gap the room temperature resistivity of $\mathrm{SiC}$ can be made to exceed $10^{10} \Omega \mathrm{cm}$ by compensating the residual shallow level impurities such as nitrogen and boron by the introduction of an appropriate deep level near the middle of the band gap. At present two approaches are being used to accomplish this. The oldest of these is to dope the material during growth with vanadium. ${ }^{1}$ Vanadium has the advantage of being amphoteric in $\mathrm{SiC}$ so that the Fermi level will be pinned at either its acceptor $\left(V^{3+/ / 4+}\right)$ or donor $\left(V^{4+/ / 5+}\right)$ level depending on whether $N_{\mathrm{SD}}-N_{\mathrm{SA}}$ is greater or less than zero, respectively, where $N_{\mathrm{SD}}$ is the total concentration of all shallow donors and $N_{\mathrm{SA}}$ is the total concentration of all shallow acceptors. But this property turns out to be a disadvantage as well since its amphoteric nature makes vanadium a very efficient electron trap which leads to degradation of the microwave properties of $\mathrm{SiC}$ transistors fabricated on top of the substrate. $^{2}$ An alternative to vanadium doping which has proven to be effective is to vary the growth conditions of undoped material to create intrinsic deep levels to compen-

${ }^{a)}$ Electronic mail: william.mitchel@wpafb.af.mil sate the residual impurities. ${ }^{3}$ Such defect compensated SI $\mathrm{SiC}$ is now commercially available as $\mathrm{SI} \mathrm{SiC:V}$.

Although extensive research has been conducted to explain the semi-insulating properties of defect compensated SI $\mathrm{SiC}$, the atomic nature of the defects pinning the Fermi level and creating the SI properties is still under debate. Many different levels have been reported ${ }^{3,4}$ and several intrinsic defects have been identified by electron paramagnetic resonance (EPR) studies ${ }^{5-7}$ but correlations between electrical and EPR experiments have been difficult to make and remain controversial. Little has been published on the actual growth processes so it is also difficult to determine if the material is silicon or carbon rich during growth. In addition, most of the reports on defect compensated $\mathrm{SI} \mathrm{SiC} \mathrm{have} \mathrm{been} \mathrm{on} \mathrm{the} 4 H$ polytype with very little reported on SI $6 H$-SiC.

We report here a study of the electronic properties of samples of $6 \mathrm{H}-\mathrm{SiC}$ grown under similar conditions with slight variations which resulted in different electrical properties. Temperature dependent Hall effect (TDH), low temperature photoluminescence (LTPL), and secondary ion mass spectrometry (SIMS) measurements were made on samples from three different wafers while thermally stimulated current (TSC) and optical admittance spectroscopy measurements were made on more resistive samples. We demonstrate that the SI properties of this material depend on a close compensation between one or more dominant deep level defects and residual nitrogen and boron impurities without other im- 
TABLE I. Boron and nitrogen SIMS results. Concentrations are in $10^{16} \mathrm{~cm}^{-3}$. No net concentration is given for sample B because the difference between nitrogen and boron concentrations is within the experimental error of the measurements.

\begin{tabular}{cccc}
\hline \hline Wafer & Total B & Total N & Net [B-N] \\
\hline C & 5.00 & 0.6 & $4.4(p)$ \\
B & 5.5 & 5.7 & \\
A & 5.0 & 31.0 & $-26.0(n)$ \\
\hline \hline
\end{tabular}

purities playing a significant role. The results presented here also demonstrate the extreme sensitivity of the electrical properties of unintentionally doped semi-insulating $\mathrm{SiC}$ to slight variations in the impurity and defect concentrations.

\section{EXPERIMENTAL DETAILS}

The $6 H$-SiC material was grown by the physical vapor transport (PVT) process at Bandgap Technologies, Inc. without intentional doping. Growth was performed in the temperature range of $2200-2400{ }^{\circ} \mathrm{C}$ under $1-10$ Torr of argon. Three separate wafers designated A, B, and C were investigated. The wafers were selected to be representative of $n$-type (A), semi-insulating (B), and $p$-type (C) material that can result from slight variations in the growth conditions. One sample from each wafer was used for TDH effect and resistivity measurements, and another for PL, optical admittance spectroscopy (OAS), and SIMS in that order. A separate sample from semi-insulating wafer B was used for TSC measurements.

For TSC experiments unannealed indium contacts were soldered onto the four corners of the sample after degreasing using organic solvents. Measurements were made using two of the four contacts. The sample was cooled from 390 to $83 \mathrm{~K}$ in the dark, during which time the dark current was measured. After illuminating the sample at $83 \mathrm{~K}$ for 5 min to fill the traps (during which time the photocurrent was recorded), the light was turned off; then, the TSC was measured upon warming at heating rates of $\beta=0.3 \mathrm{~K} / \mathrm{s}$ and under biases of $V_{b}=5-40 \mathrm{~V}$. The photoluminescence experiments were carried out at $4.2 \mathrm{~K}$ on as-received samples. Prior to depositing Ohmic and Schottky contacts for TDH and OAS experiments, respectively, the samples were given a wet oxidation at $1150{ }^{\circ} \mathrm{C}$ for several hours followed by an $\mathrm{HF}$ etch to remove residual polishing damage. Different Ohmic contact metals for the van der Pauw TDH samples were used for samples from each wafer, depending on its suspected conduction type, Ni for A ( $n$ type), Ta/NiCr/W for $\mathrm{B}$ (semi-insulating), and $\mathrm{Al} / \mathrm{W}$ for $\mathrm{C}$ ( $p$ type). Contacts were annealed in forming gas at $925^{\circ} \mathrm{C}$ for $2 \mathrm{~min}$ after which gold was deposited on the $\mathrm{Ta} / \mathrm{NiCr} / \mathrm{W}$ and $\mathrm{Al} / \mathrm{W}$ samples for high temperature TDH measurements. Separate TDH systems were used for measurements above and below room temperature. Unannealed transparent indium tin oxide was used for OAS Schottky contacts. A Cameca IMS4FE7 SIMS instrument was used to determine nitrogen and boron concentrations.

The carrier concentration versus inverse temperature data for the $n$ - and $p$-type samples were fitted to the charge

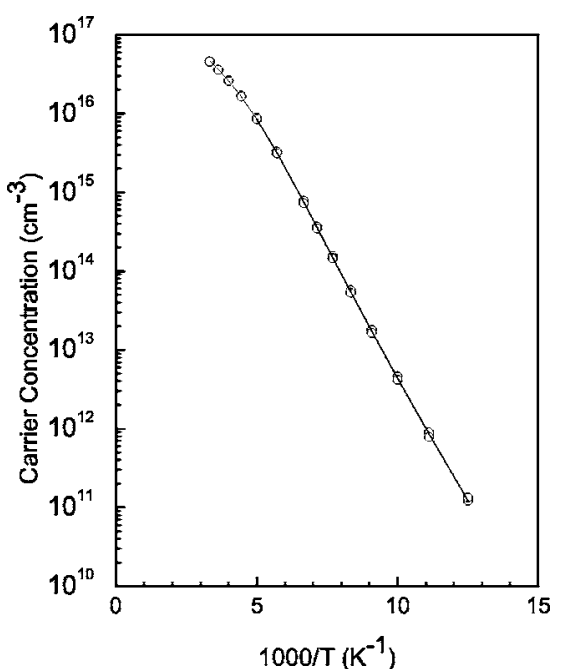

FIG. 1. Electron concentration vs inverse temperature, with fitting results (solid line) for sample A.

balance equation using a least squares procedure to determine the dominant defect concentration and activation energy and the compensation. The electron and hole effective masses were 0.648 and 1.68 , respectively, which were taken from the data of Iwata. ${ }^{8}$ The conduction band minima parameter was taken to be 6 . The Hall scattering factor was assumed to be 1 and the degeneracy factor, $g$, was taken to be 2 for donors and 4 for acceptors.

\section{RESULTS}

SIMS measurements of nitrogen and boron concentrations were made on samples from all three wafers. The results are summarized in Table I. Boron concentration was similar in all three wafers at around $5 \times 10^{16} \mathrm{~cm}^{-3}$. The nitrogen concentration, however, varied significantly among the three wafers from a low of $6 \times 10^{15} \mathrm{~cm}^{-3}$ in the $p$-type sample to a high of $3.1 \times 10^{17} \mathrm{~cm}^{-3}$ in the $n$-type sample. Also included in Table I are the differences between boron and nitrogen concentrations for each wafer. Boron is usually assumed to be a contaminant in the starting material while the nitrogen most likely comes from atmospheric contamination of the graphite furnace elements and is depleted during growth so its concentration decreases over time. One would expect starting material from the same source to result in similar boron levels. We note that the $\mathrm{B}$ and $\mathrm{N}$ concentrations in the samples under study here are significantly higher than the levels in high purity semi-insulating $4 \mathrm{H}-\mathrm{SiC}^{3}$

Carrier concentration versus inverse temperature from TDH measurements of samples $\mathrm{A}$ and $\mathrm{C}$ are shown in Figs. 1 and 2. The solid lines are the fits to the charge balance equation. As expected from the SIMS results, A is $n$ type and C is $p$ type. Sample B was too resistive to measure at room temperature and the Hall voltages at elevated temperatures were too noisy to permit accurate measurement of the Hall coefficient so instead of the carrier concentration the resistivity is plotted versus inverse temperature in Fig. 3. An activation energy of $1.023 \mathrm{eV}$ was determined from the resistivity by fitting the expression ${ }^{9} \ln \left(\rho^{-1} T^{-1.5}\right)=A-E_{a} / k T$. This value is comparable with activation energies seen in undoped semi- 


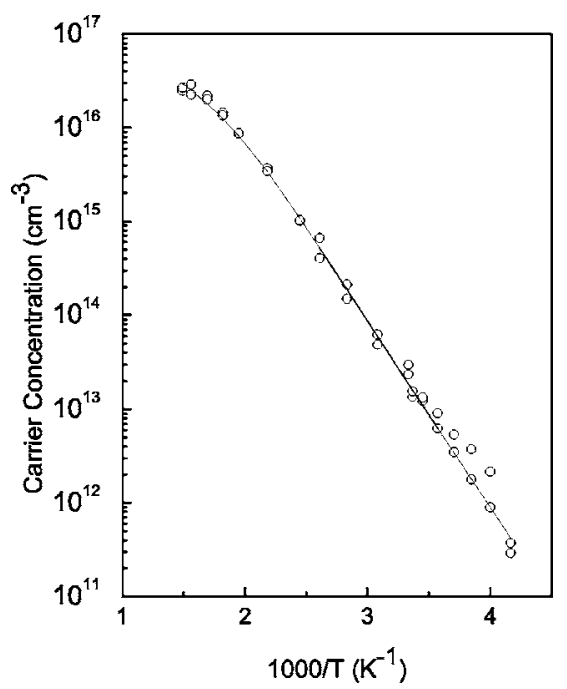

FIG. 2. Hole concentration vs inverse temperature, with fitting results (solid line) for sample $\mathrm{C}$.

insulating 4H-SiC samples. ${ }^{3,4}$ The fitting results for samples $\mathrm{A}$ and $\mathrm{C}$ are given in Table II along with the carrier type and room temperature resistivity. The best fit for A was for two donor levels at $E_{C}-0.103$ and $E_{C}-0.150 \mathrm{eV}$. It is assumed that these two levels are due to nitrogen but it should be noted that the activation energies are slightly high compared to the accepted values for nitrogen on the hexagonal $(0.085 \mathrm{eV})$ and cubic $(0.125 \mathrm{eV})$ lattice sites. ${ }^{10}$ The concentrations of the two levels are in excellent agreement with the expected 1:2 ratio for one hexagonal and two cubic lattice sites in $6 H-\mathrm{SiC}$, and the sum of the two concentrations, which is the total nitrogen concentration, is in general agreement with the SIMS results for this wafer. The boron concentration from SIMS, $5 \times 10^{16} \mathrm{~cm}^{-3}$, is slightly higher than the total compensating acceptor concentration, 3.6 $\times 10^{16} \mathrm{~cm}^{-3}$, from $\mathrm{TDH}$, but within the usual variation in compensation values from $\mathrm{TDH}$ fitting. The best fit for $p$-type sample $\mathrm{C}$ was a single acceptor level at $E_{V}$

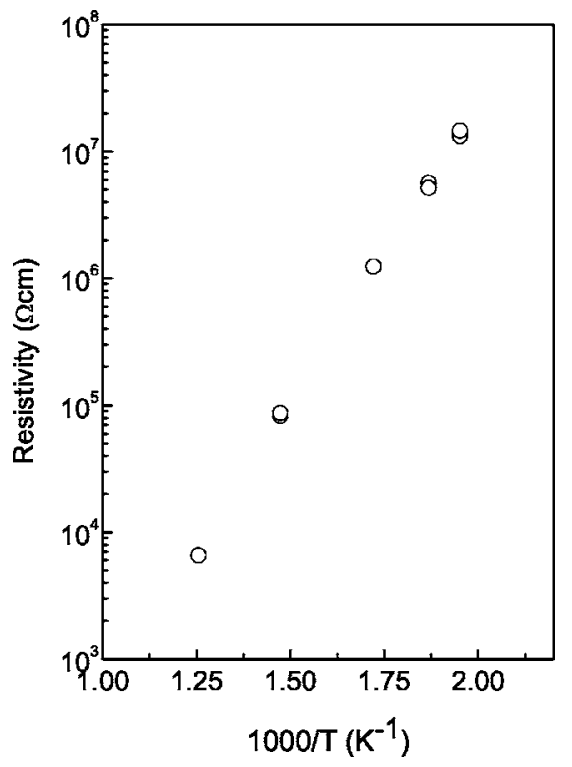

FIG. 3. Resistivity vs inverse temperature for semi-insulating sample B.
TABLE II. Hall effect fitting results. $\rho^{300 \mathrm{~K}}$ is the room temperature resistivity, $N_{\text {comp }}$ is the concentration of all the compensating centers (acceptors for $n$ type and donors for $p$ type), and $N_{i}$ and $E_{i}$ are the concentration and activation energy for the $i$ 's level in the fit.

\begin{tabular}{ccc}
\hline \hline Sample & $\mathrm{A}$ & $\mathrm{C}$ \\
\hline Carrier type & $n$ & $p$ \\
$\rho_{300 \mathrm{~K}}(\Omega \mathrm{cm})$ & 0.65 & 6100 \\
$N_{\text {comp }}\left(\mathrm{cm}^{-3}\right)$ & $3.63 \times 10^{16}$ & $2.21 \times 10^{16}$ \\
$N_{1}\left(\mathrm{~cm}^{-3}\right)$ & $4.08 \times 10^{16}$ & $8.66 \times 10^{16}$ \\
$E_{1}(\mathrm{eV})$ & 0.103 & 0.357 \\
$N_{2}\left(\mathrm{~cm}^{-3}\right)$ & $8.43 \times 10^{16}$ & $\cdots$ \\
$E_{2}(\mathrm{eV})$ & 0.150 & $\cdots$ \\
\hline \hline
\end{tabular}

$+0.357 \mathrm{eV}$. This is within the accepted range $(0.27-0.38 \mathrm{eV})$ of activation energies for boron in $6 \mathrm{H}-\mathrm{SiC}{ }^{10}$ The boron and compensating donor concentrations from $\mathrm{TDH}, 8.6 \times 10^{16}$ and $2.2 \times 10^{16} \mathrm{~cm}^{-3}$, respectively, are again in rough agreement with the SIMS results for boron and nitrogen concentrations, $5.0 \times 10^{16}$ and $3.3 \times 10^{16} \mathrm{~cm}^{-3}$, respectively.

The mobility versus temperature results for $\mathrm{A}$ and $\mathrm{C}$ are shown in Fig. 4. The electron mobility in $\mathrm{A}$ is about $200 \mathrm{~cm}^{2} / \mathrm{V} \mathrm{s}$ at room temperature, which can be compared to the commonly referenced value of $400 \mathrm{~cm}^{2} / \mathrm{V} \mathrm{s}$. The hole mobility in $\mathrm{C}$ of about $65 \mathrm{~cm}^{2} / \mathrm{V}$ s at room temperature compares favorably with the referenced value of $90 \mathrm{~cm}^{2} / \mathrm{V} \mathrm{s}$.

The 4.2 K PL results for the three wafers in this study are presented in Fig. 5 for the near infrared region around $0.8-1.6 \mathrm{eV}$. Present in all three samples are lines labeled UD-1 (0.9955 and a doublet at $1.0015 \mathrm{eV}$ ) and UD-3 (a nophonon line at $1.3435 \mathrm{eV}$ with phonon lines at $1.258 \mathrm{eV}) .{ }^{11,12}$ The only other identifiable lines are those due to very low concentrations of vanadium in sample $\mathrm{A}$ at 0.8947 and $0.9478 \mathrm{eV} .{ }^{13}$ The intensities of the vanadium lines are very weak compared to what is seen in intentionally doped material and are close to the SIMS detection limit. We note that the absence of vanadium PL is very rare in PVT grown SiC. The intensity of the UD-1 lines varied dramati-

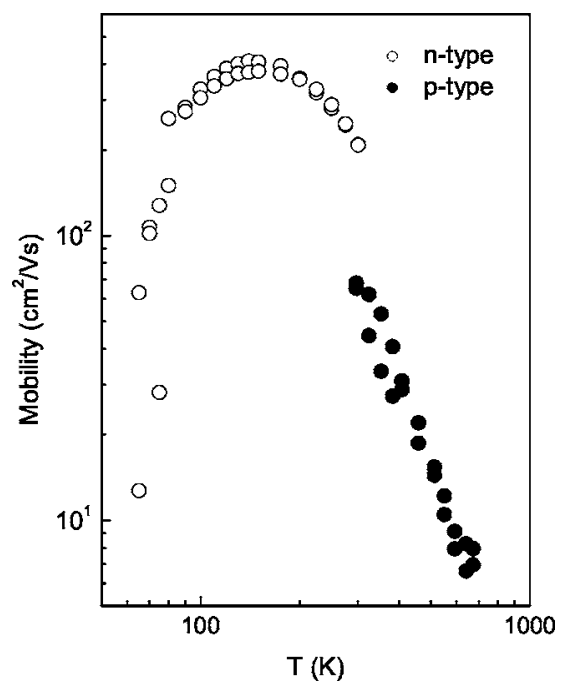

FIG. 4. Electron and hole mobilities vs temperature for A and C, respectively. 


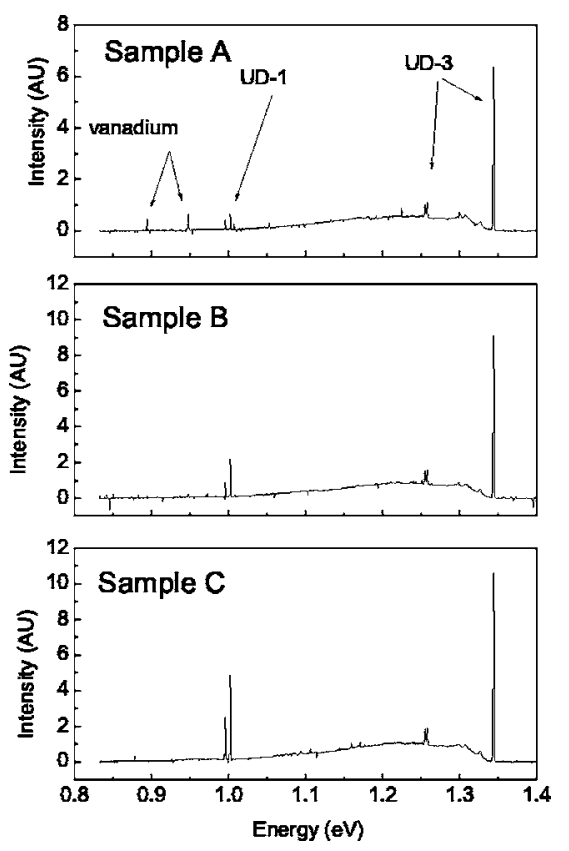

FIG. 5. Low temperature photoluminescence results in the near IR region for samples $\mathrm{A}, \mathrm{B}$, and $\mathrm{C}$ showing the presence of vanadium, UD-1, and UD-3.

cally among the three samples, from about 0.72 in $n$-type sample A to 5.0 in the $p$-type sample C, while UD-3 shows a much smaller variation, from 6.4 to 10.8 . It should also be noted that the commonly observed UD-2 (Ref. 11) is not detected. The very broad feature from 1.0 to $1.35 \mathrm{eV}$ is usually associated with UD-3. The identities of the defects responsible for UD-1 and UD-3 are still under debate.

TSC is useful for identifying compensated traps and other defect levels in semi-insulating material. ${ }^{14}$ The ionized traps are filled at low temperature by white light illumination then emptied by a temperature scan in the dark during which variations in the current indicate the presence of traps. The TSC temperature scan for the semi-insulating sample is shown in Fig. 6. Here the net TSC signal is plotted. This is

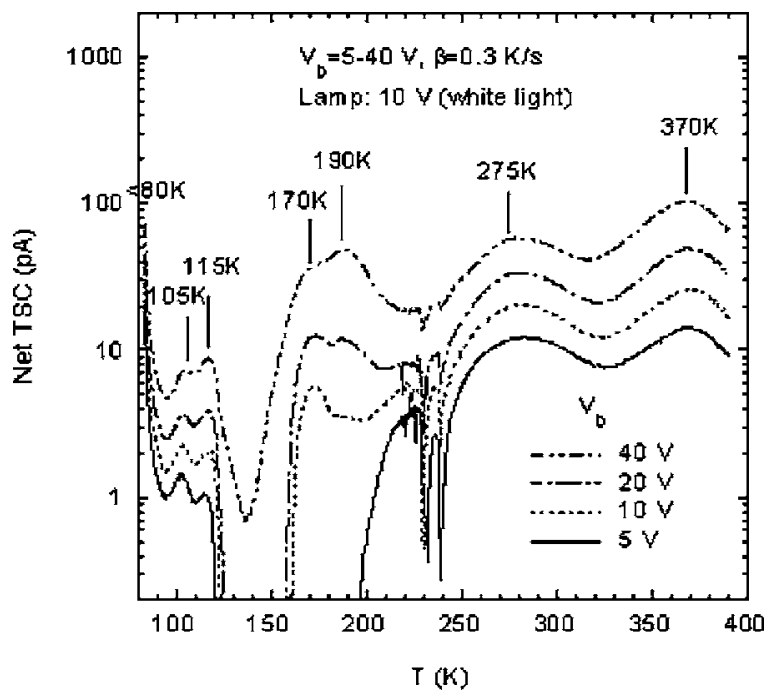

FIG. 6. Net TSC spectra for sample B as a function of bias voltage after white light illumination with a heating rate of $0.3 \mathrm{~K} / \mathrm{s}$. This is the TSC signal with the monotonic background subtracted.

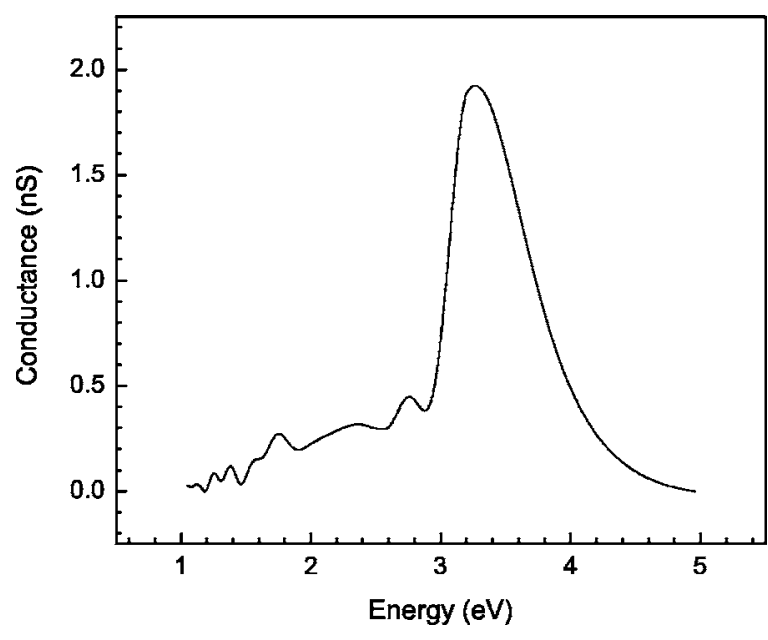

FIG. 7. OAS spectra for semi-insulating sample B.

the as measured signal minus the monotonic background, which is due to thermal ionization from the deep level which controls the Fermi level. At least seven features, at $<80,105$, $115,170,190,275$, and $370 \mathrm{~K}$, can be observed. The feature at $<80 \mathrm{~K}(<0.12 \mathrm{eV})$ could be due to $\mathrm{N}$, the features at $105 \mathrm{~K}(0.18 \mathrm{eV})$ and $115 \mathrm{~K}(0.20 \mathrm{eV})$ are due to a relatively shallow level, possibly $\mathrm{Al}$ on different sites but $\mathrm{Al}$ was not detected by SIMS. The features at $170 \mathrm{~K}(0.32 \mathrm{eV})$ and $190 \mathrm{~K}(0.36 \mathrm{eV})$ are as yet unidentified. The feature at $275 \mathrm{~K}(0.56 \mathrm{eV})$ could be due to the boron related $D$ center and the feature at $370 \mathrm{~K}(0.79 \mathrm{eV})$ is as yet unidentified but might be due to the vanadium acceptor level. The TSC signals were found to be proportional to the bias, except for features at $170 \mathrm{~K}$ and $190 \mathrm{~K}$, which is called the biasenhancement effect.

While OAS, which can be used to identify deep levels present in semiconductors, does not provide as much information on defects as, say, deep level transient spectroscopy which gives both concentrations and capture cross sections as well as trap energy, OAS has the benefits of being able to measure very deep levels without going to extremely high temperatures and being able to be applied directly to semiinsulating samples. This technique has proven useful in measurement of vanadium doped semi-insulating $\mathrm{SiC}$ where optical transitions have been correlated with vanadium related deep levels identified in TDH experiments. ${ }^{9}$ However, measurement of deep, midgap levels in undoped semi-insulating $\mathrm{SiC}$ has proven more difficult. Many samples that were studied in this laboratory, including the sample from wafer B in this study, had no or very weak OAS response in the region around the Fermi level. This can be seen in Fig. 7. The response in the region from $1 \mathrm{eV}$ to the band edge is very weak and not reproducible. Vanadium, chromium, and titanium would have measurable responses in this region if they were present in high concentrations.

\section{DISCUSSION}

The inability of presently available techniques to determine the concentration of the dominant deep level in semiinsulating $\mathrm{SiC}$ has hindered the development of a reliable compensation model. Further complicating the situation is 
the fact that it is not even known whether the deep level or levels are donor- or acceptorlike. The experiments presented above, taken together, can provide some information on the compensation question.

The SIMS boron concentration in the $n$-type wafer and the nitrogen concentration in the $p$-type wafer are very close to the compensating acceptor and donor concentrations, respectively, from the TDH fitting for the same wafers. This means that the total of all acceptorlike centers other than boron in $n$-type material and the total of all donorlike centers other than nitrogen in $p$-type are at most in the low $10^{16} \mathrm{~cm}^{-3}$ range. This conclusion is supported by the results of the OAS experiments on the semi-insulating sample. The absence of a strong extrinsic signal in the OAS spectrum in Fig. 7 suggests that transition metal deep levels do not play a strong role in the compensation mechanism in this material. The TSC results are, however, hard to reconcile with this. There are certainly a large number of compensated centers in the semi-insulating material and the peak heights suggest they are on the rough order of the boron concentration. Further investigation of the TSC results is required. Nonetheless, the concentration of the $1.0 \mathrm{eV}$ deep level in the semiinsulating sample must be at least on the order of the high $10^{15} \mathrm{~cm}^{-3} \mathrm{~s}$ to compensate the nitrogen and boron levels that are nearly equal in the semi-insulating sample so that the material will be semi-insulating. Furthermore, unless the concentration of this level is unusually high in the semiinsulating material as opposed to the conducting material, which was grown under similar growth conditions, its concentration cannot be higher than the low $10^{16} \mathrm{~cm}^{-3} \mathrm{~s}$ or else it would show up in the compensating centers in the TDH fitting for either the $n$ - or $p$-type samples, depending on whether it is acceptor- or donorlike. Of course, the center could be an amphoteric defect that takes on either donor or acceptor properties depending on the position of the Fermi level but in that case it would affect the compensation in both the $n$ - and $p$-type samples if its concentration was on the order of the boron or nitrogen concentration. Jenny et al. ${ }^{3}$ have demonstrated that in their high purity $\mathrm{SI} 4 \mathrm{H}-\mathrm{SiC}$ several different deep levels can pin the Fermi level in different samples. The question this suggests is whether or not all these levels are present in the material at the same time. Again, unless all the concentration of all these levels peak in the semi-insulating material under study here one would expect them to add to the compensating centers in either the $n$ or $p$-type sample and the results here do not support that.

There is still an ongoing debate over the identity of the UD PL lines. The only identification that has gained wide spread acceptance is that of UD-2 with the $V_{\mathrm{C}} V_{\mathrm{Si}}$ divacancy ${ }^{15}$ but that line is not observed in the material under study here. The UD-3 defect appears to be relatively constant in all three samples while UD-1 varies. The relative concentrations are hard to extract from the PL data for a variety of reasons. Further studies of these PL lines with electrical measurements are required before either of them can be correlated with the dominant deep level in this or any semi-insulating material.

\section{CONCLUSIONS}

The electronic properties of $6 \mathrm{H}$-SiC samples grown under similar conditions without intententional doping have been measured by a variety of techniques. Slight variations in the growth conditions resulted in $n$-type, $p$-type or semiinsulating material. LTPL in the near IR region detected low concentrations of vanadium and the defects denoted UD-1 and UD-3. UD-1 was strongest in the $n$-type wafer and weakest in the $p$-type wafer while UD-3 had less dramatic sample to sample variations. The total concentration of compensated acceptors and donors in the $n$-type and $p$-type materials, respectively, have been shown to be close to the boron and nitrogen concentrations determined by SIMS. The results suggest that a single deep level with a concentration in the high $10^{15}$ to low $10^{16} \mathrm{~cm}^{-3}$ range is responsible for the semi-insulating properties of this material and that compensation is due almost entirely to the nitrogen and boron impurities and that other impurities and defects are not present in high enough concentrations to affect the compensation in this material.

\section{ACKNOWLEDGMENTS}

The authors wish to thank D. Dorsey for supporting this project. The technical support of G. Landis and W. Rice is gratefully appreciated. The work of two of the authors (S.R.S. and H.E.S.) was supported by USAF Contract No. F33615-00-C-5422 while the work of two other authors (D.C.L. and Z.Q.F.) was supported by USAF Contract No. F33615-00-C-5402 and by ONR DURINT Contract No. N00014-01-1-0715.

${ }^{1}$ H. McD. Hobgood, R. C. Glass, G. Augustine, R. H. Hopkins, J. Jenny, M. Skowronski, W. C. Mitchel, and M. Roth, Appl. Phys. Lett. 66, 1364 (1995).

${ }^{2}$ N. Sghaier, J.-M. Bluet, A. Souifi, G. Guillot, E. Morvan, and C. Brylinski, IEEE Trans. Electron Devices 50, 297 (2003).

${ }^{3}$ J. R. Jenny, St. G. Müller, A. Powell, V. F. Tsvetkov, H. M. Hobgood, R. C. Glass, and C. H. Carter, Jr., J. Electron. Mater. 31, 366 (2002).

${ }^{4}$ W. C. Mitchel, W. D. Mitchell, M. E. Zvanut, and G. Landis, Solid-State Electron. 48, 1693 (2004)

${ }^{5}$ N. T. Son, B. Magnusson, Z. Zolnai, A. Ellison, and E. Janzén, Mater. Sci. Forum 457-460, 437 (2004).

${ }^{6}$ E. N. Kalabukhova, S. N. Lukin, A. Saxler, W. C. Mitchel, S. R. Smith, J. S. Solomon, and A. O. Evwaraye, Phys. Rev. B 64, 235202 (2001).

${ }^{7}$ M. E. Zvanut, V. V. Konovalov, H. Wang, W. C. Mitchel, W. D. Mitchell, and G. Landis, J. Appl. Phys. 96, 5484 (2004).

${ }^{8}$ H. P. Iwata, Appl. Phys. Lett. 82, 598 (2003).

${ }^{9}$ W. C. Mitchel, R. Perrin, J. Goldstein, A. Saxler, M. Roth, S. R. Smith, J. S. Solomon, and A. O. Evwaraye, J. Appl. Phys. 86, 5040 (1999).

${ }^{10}$ Properties of Advanced Semiconductor Materials, edited by M. E. Levinshtein, S. L. Rumyantsev, and M. S. Shur (Wiley, New York, 2001), p. 104.

${ }^{11}$ B. Magnusson, A. Ellison, N. T. Son, and E. Janzén, Mater. Res. Soc. Symp. Proc. 640, H7.11.1 (2001).

${ }^{12}$ Mt. Wagner, B. Magnusson, W. M. Chen, and E. Janzén, Phys. Rev. B 66, 115204 (2002).

${ }^{13}$ J. Schneider, H. D. Müller, K. Maier, W. Wilkening, F. Fuchs, A. Dörnen, S. Liebenzeder, and R. Stein, Appl. Phys. Lett. 56, 1184 (1990).

${ }^{14}$ Z.-Q. Fang, B. Claflin, D. C. Look, L. Polenta, and W. C. Mitchel, J. Electron. Mater. 34, 336 (2005).

${ }^{15}$ See B. Magnusson, Proceedings of the International Conference on $\mathrm{SiC}$ and Related Materials, 2005 (unpublished). 